\title{
Exploration and Sampling of the BK02 Kimberlite, Orapa Kimberlite Field, Botswana
}

\author{
George Q.J. Pybus, Kabelo Tiyedze, John Armstrong
}

Lucara Diamonds PtyLtd, GPybus@BotetiMining.co.bw

The BK02 kimberlite was first discovered in the late 1960's. Preliminary work consisted of pit excavation and limited drilling. Subsequent work was conducted in the early to mid-2000's with limited ground geophysics, trenching and drilling. Lucara Diamond acquired a prospecting license in 2014 and proceeded with a program of ground geophysics, surface trenching mini-bulk sampling and core drilling. Previous operator's results indicated the kimberlite was diamondiferous, published results were interpreted by Lucara to suggest the presence of geological similarities to the AK6 kimberlite (Karowe Mine).

The BK02 kimberlite has a surface area of approximately 2.4 ha expressed by a high contrast strong magnetic dipole. BK02 is capped by a calcrete layer and since historical works appear to have included significant disturbance of that, there is a slight topographic high marking the central area of the kimberlite. This may be related to the disturbance, rather than a natural feature of the occurrence.
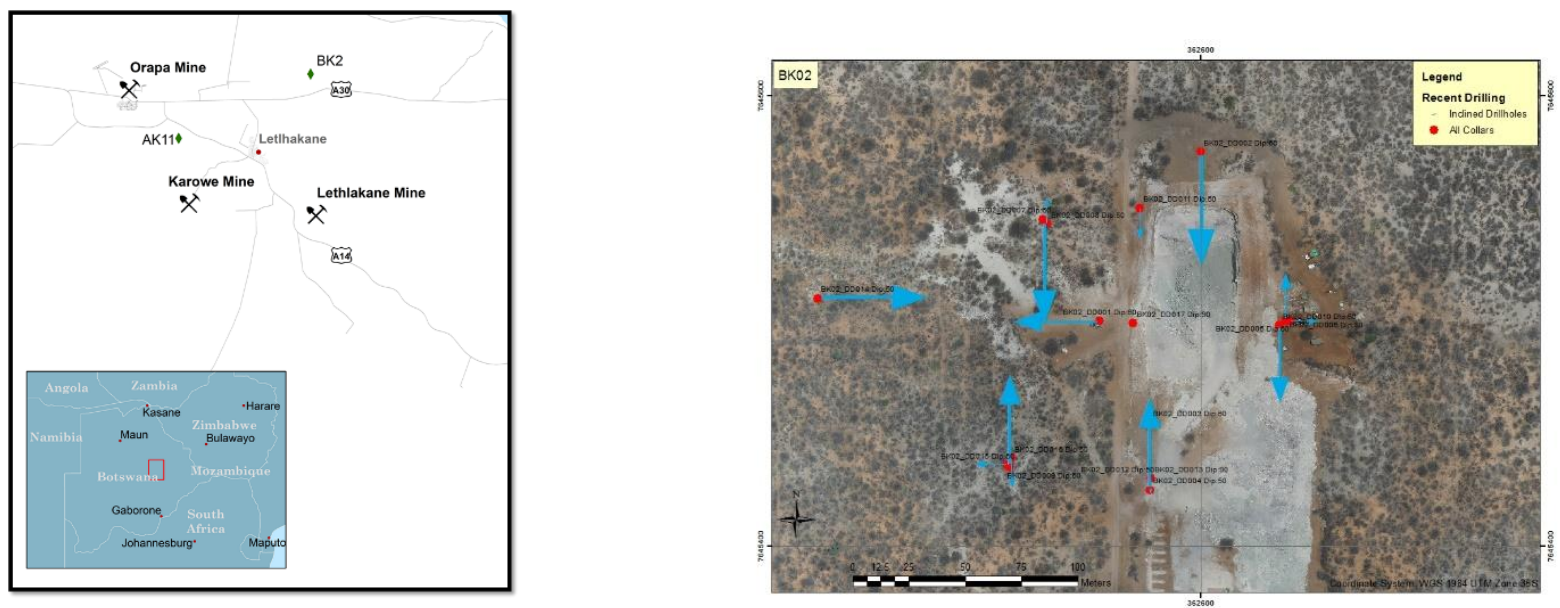

Figure 1: General Location of BK02 and location of drill-holes completed in 2016-2017.

BK02 is described as a magmatic kimberlite intruded into basalts, which are up to 30 meters thick in current drill holes, underlain by sediments (sandstones and deeper siltstones and mudstones, tentatively assigned to the Ntane and Mosolotsane Formations respectively).

A total of $~ 11,000$ tonnes of kimberlite have been processed from BK02 in two samples, confirming a coarse diamond size distribution. The combined results from BK02-1 and BK02-2 samples are presented in Table 1, a total of 584.12 carats have been recovered from 10,937 tonnes of kimberlite for a sample grade of $5.3 \mathrm{cpht}$. A total of 46 diamonds have been recovered greater than 1 carat in weight, including 8 diamonds greater than 2 carats in weight.

Table 1. Combined BK02-1 and BK02-2 Samples

\begin{tabular}{|c|c|c|c|c|c|c|c|c|c|c|c|c|}
\hline SAMPLE & $\begin{array}{l}\text { SAMPLE } \\
\text { TONNES }\end{array}$ & $+21 \mathrm{DTC}$ & +19DTC & +17DTC & +15DTC & $+13 \mathrm{DTC}$ & +11DTC & +9DTC & $+7 \mathrm{DTC}$ & $+5 \mathrm{DTC}$ & $+3 \mathrm{DTC}$ & -3DTC \\
\hline BK02 Total & 10937 & 10.04 & 24.17 & 10.965 & 23.26 & 57.53 & 103.1 & 96.92 & 67.29 & 114.36 & 53.93 & 22.54 \\
\hline
\end{tabular}

Three largest diamonds recovered, 5.48, 4.56, 2.71 carats

The diamonds recovered are scheduled to be independently valued early in the second quarter of 2017 .

A total of 17 drill holes totalling 1,990 metres were drilled into the BK02 kimberlite during 2016 and Q1 2017. A total of 1059 metres of kimberlite were intersected with the deepest intersection of $201 \mathrm{~m}$ 
in a vertical PQ diamond drill hole, drilled adjacent to the surface mini-bulk sample excavation. The interpreted surface area of BK02 is 2.1 hectares and additional delineation drilling is required to finalise certain parts of the interpretation (data from Lucara Mining Press Release, $6^{\text {th }}$ March 2017)

Observations from drill core suggest that the present-day exposure is close to the basalt/sediment contact with a slightly complicated present day surface expression with basalt breccia/cap on the north and a slightly flaring intrusion to the south. Drilling intersected thicker basalt to the north, slightly thinner to east and west, none to the south. This is currently interpreted to represent a thinning of the basalt in the area and it is proposed that the kimberlite flared along the basalt/sandstone contact toward the south. Additional drilling is required to resolve this geometry. The TMI dipole anomaly is significantly stronger on the eastern side, and this is reflected in raised magnetic susceptibilities observed in drill-holes through this part of the kimberlite.
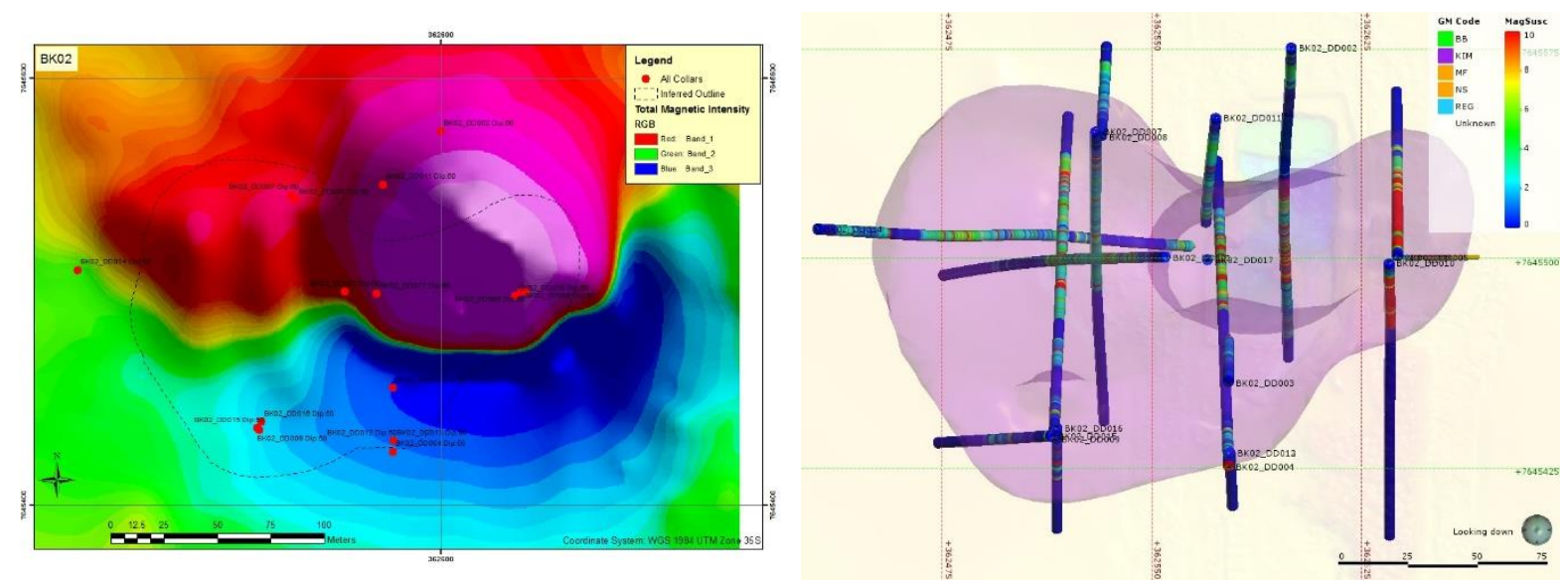

Figure 2: Left: Ground magnetic data total magnetic intensity image with drill hole collars and surface outline from 3d model based on drill-holes. Right: Plan view looking down on the model of the kimberlite, boreholes shown with Magnetic Susceptibility values, note abundance of values greater than 10SI units to the east.

The pipe infill is dominated by a homogenous PK to MK intrusion with minor textural variations and variable extents of weathering, mainly hydration, as indicated by the presence of saponite and montmorillonite (after serpentine, after olivine). The eastern portion (BK02_DD006) appears less weathered, and more coherent than the western portion (BK02_DD001 and BK02_DD007).

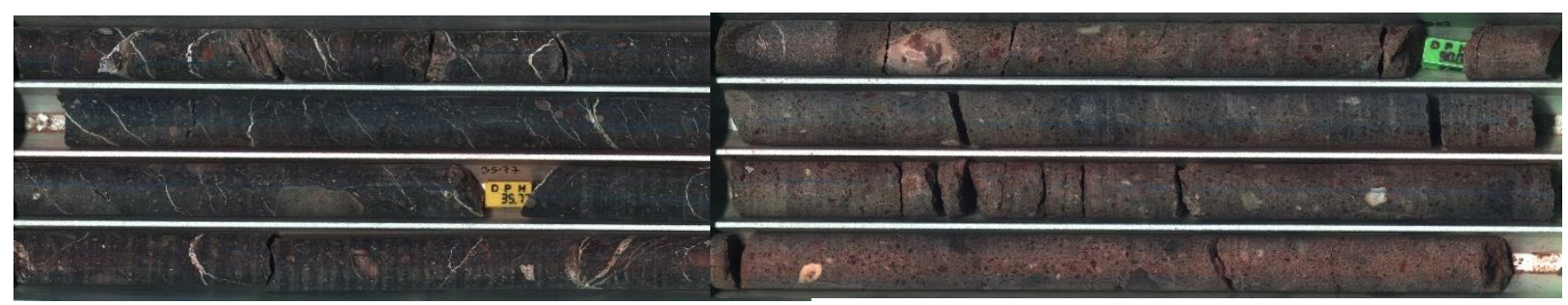

Figure 3: Left: Tray 8 from BK02_DD006 showing eastern kimberlite 33.45m to 36.97m; Right: Tray 27 from BK02 DD007 showing western more weathered less coherent kimberlite, depth $89.19 \mathrm{~m}$ to $92.79 \mathrm{~m}$

The contact between the kimberlite and sediments (sandstones) is complicated in the west and southwest, as seen in BK02_DD001 and BK02_DD009, e.g. Figure 4. 


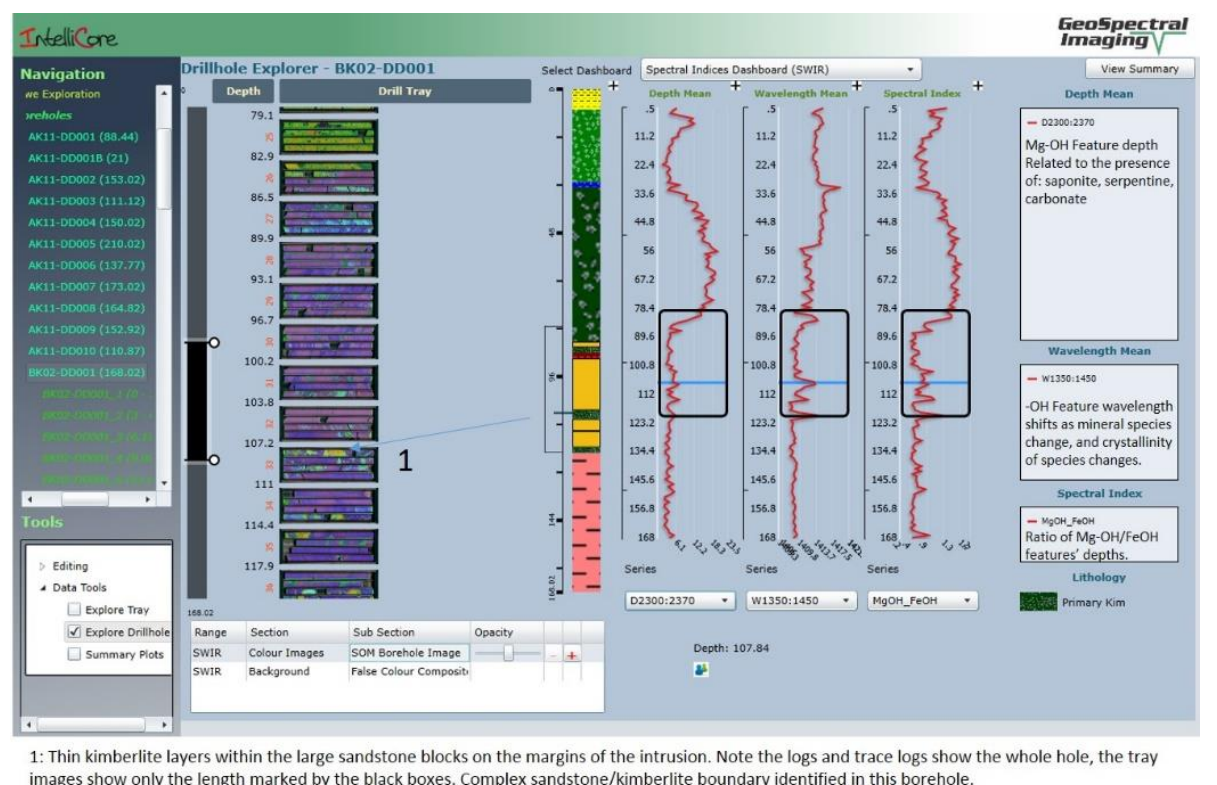

Figure 4: Core imaging data showing core trays with an automatic classification image showing kimberlite (top and thin layers through the images) and sandstone and shales on the western margin of the kimberlite

Results from a hyperspectral imaging of 1667 metres of core including country rock and kimberlite, that was undertaken in Dec/16 will be presented to enhance the preliminary 3-d model of the BK02 kimberlite, particularly internal geology. This seems to indicate a similar distinction as the magnetic susceptibility, with a variation in the spectral response between the eastern and western parts of the kimberlite (Figure 5: depth of $\mathrm{OH}$ feature modelled volumes). The imaging was completed in Dec 2016 and therefore excludes 4 holes that were drilled in 2017. The western portion of the kimberlite is therefore data-sparse and modelling has very low confidence.

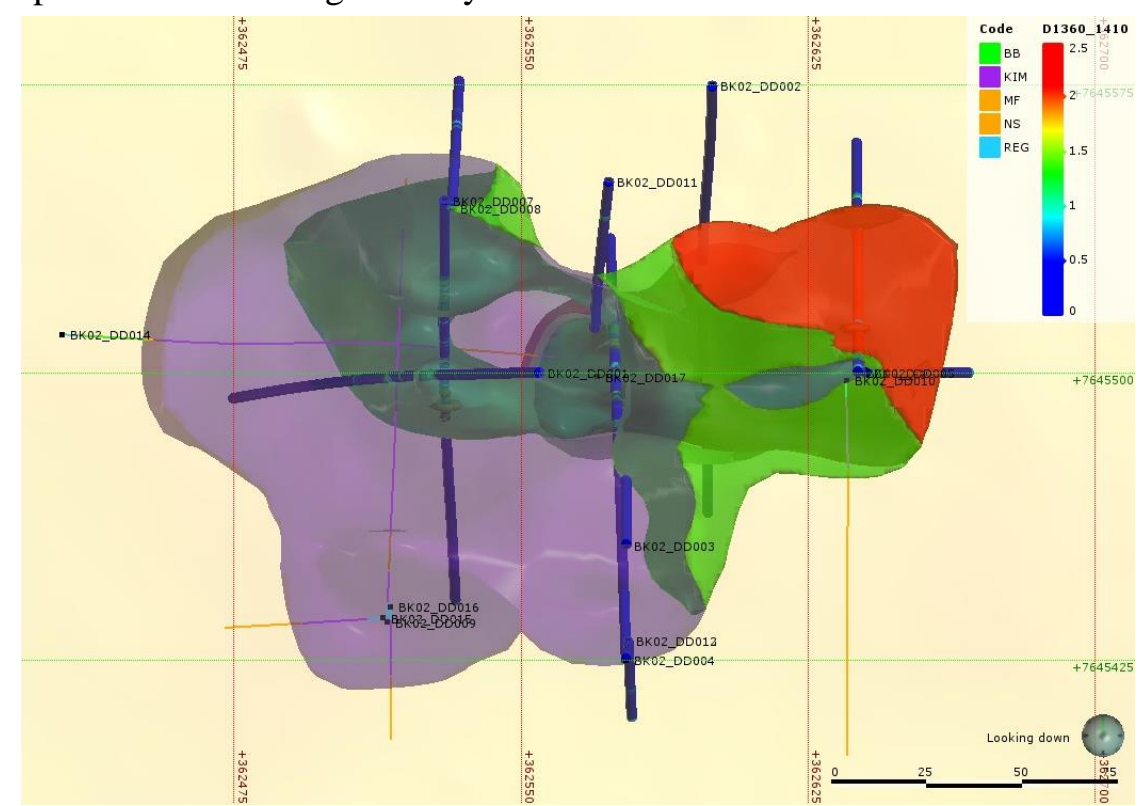

Figure 5:Plan view of 3d model of internal variation of the depth of the hydroxyl absorption feature within BK02. The data is collected on a line by line basis, and calculated to represent a $1 \mathrm{~m}$ interval by averaging the depth of the feature for all pixels within the selected interval. Holes with no reflectance data are shown with lithology.

New modern diamond processing and drilling information have enhanced the understanding of diamond content and intrusive history of the BK02 kimberlite. 